Article

\title{
Process Technology, Applications and Thermal Resistivity of Basalt Fiber Reinforced SiOC Composites
}

\section{Rainer Gadow *, Patrick Weichand and Miguel Jiménez}

Institute for Manufacturing Technologies of Ceramic Components and Composites, University Stuttgart, Allmandring 7b, D-70569 Stuttgart, Germany; patrick.weichand@ifkb.uni-stuttgart.de (P.W.); miguel.jimenez@ifkb.uni-stuttgart.de (M.J.)

* Correspondence: rainer.gadow@ifkb.uni-stuttgart.de

Received: 18 March 2019; Accepted: 15 April 2019; Published: 17 April 2019

\begin{abstract}
Promising lightweight composite materials, bridging the gap between Polymer and Ceramic Matrix Composites, are manufactured as polymer derived ceramics by the use of polysiloxanes and basalt fibers. Such competitive free formable Hybrid Composites are supposed to be capable for lightweight applications in a temperature range between $300^{\circ} \mathrm{C}$ and $850^{\circ} \mathrm{C}$ and short time exposure up to over $1000^{\circ} \mathrm{C}$, even in oxidative atmosphere. Cheap raw materials like basalt fibers and siloxane resins in combination with performing manufacturing technologies can establish completely new markets for intermediate temperature composites. These attributes enable the Hybrid Composites as ideal material for fire retardant applications in automotive engineering and public transportation, as well as in fire protection systems in electrical and civil engineering applications. In this study, the most prominent fields of application and engineering solutions for Hybrid-CMC are reviewed and the results of the thermal resistivity analysis effectuated on basalt fiber reinforced SiOC samples are presented. This study consisted of several air exposures between $1 \mathrm{~h}$ and $50 \mathrm{~h}$ and temperatures in the range of $650{ }^{\circ} \mathrm{C}$ to $1100^{\circ} \mathrm{C}$. Remaining mechanical resistance was characterized by Impulse Excitation Technique (IET) and Interlaminar Shear Strength (ILSS) tests. Basalt fiber reinforced samples exhibited a decent level of mechanical performance even after the most demanding exposures. Due to the poor oxidation resistance of carbon fibers, $\mathrm{C}_{\mathrm{f}} / \mathrm{SiOC}$ composites were completely degraded after long-term exposure at $500{ }^{\circ} \mathrm{C}$ in air.
\end{abstract}

Keywords: Hybrid Composites; CMC; Basalt fiber; SiOC; fire retardant applications; lightweight

\section{Introduction}

The increasing interest in lightweight design and engineering has motivated various efforts in research and development of innovative production processes for carbon fiber reinforced plastics (CFRP). These Polymer Matrix Composites (PMC) exhibit low density in combination with superior strength and high modulus. For this reason, CFRP are nowadays not only employed in typical lightweight sectors like aviation, but in almost all industrial fields, including ground transportation and even the leisure and sports good market. An important limitation of CFRP is their low thermal and thermochemical stability. Standard matrix materials for these composites, e.g., epoxy, are suitable only up to temperatures about $140{ }^{\circ} \mathrm{C}$ (see Figure 1) [1]. Special high end polymers, e.g., polyether ether ketone (PEEK) or polyimides (PI), are capable for service temperatures up to $280^{\circ} \mathrm{C}$ [1], at much higher cost and process complexity. The lack of adequate wear resistance and a constricted chemical resistivity are further handicaps of most PMC materials. 

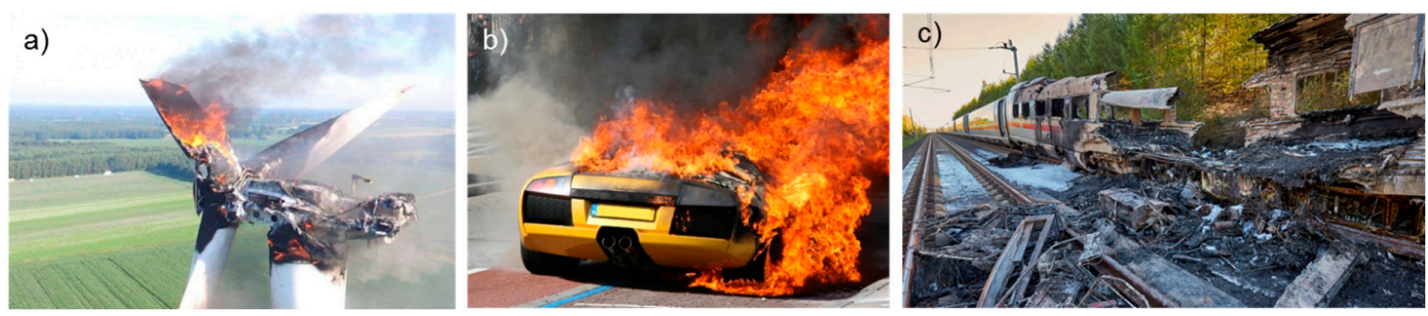

Figure 1. Fire of Polymer Matrix Composites (PMC) components with low thermal resistivity: (a) Wind turbine [2]; (b) Lamborghini Murcielago [3]; (c) Intercity-Express high speed train [4].

Advanced CMC (Ceramic Matrix Composites) exhibit a much higher temperature and wear resistance in combination with pseudo-ductile failure mechanisms and an increased toughness in comparison with bulk ceramics. Well known examples for CMC are, among others, alumina-fiber reinforced alumina (ox/ox), carbon fiber reinforced silicon carbide $(\mathrm{C} / \mathrm{SiC})$, and carbon fiber reinforced carbon $(\mathrm{C} / \mathrm{C})$. The extremely high specific heat and low coefficient of linear expansion of $\mathrm{C} / \mathrm{C}$ make them the most common material choice for brake rotors in civil and military aircrafts. These brake assemblies achieve temperatures of $500{ }^{\circ} \mathrm{C}$ in a normal landing operation and up to $1300{ }^{\circ} \mathrm{C}$ in the case of rejected take-off [5]. Besides their use in aviation and astronautic industries, $\mathrm{CMC}$ are also employed as lightweight brake rotors in sports cars [6]. Processing-routes of these composites are typically hot pressing, chemical vapor infiltration (CVI) or reaction bonding (RB) by liquid silicon infiltration (LSI). Reinforcing fibers enduring high service temperatures and harsh manufacturing conditions are predominantly very expensive ceramic fibers based on silicon carbide or alumina. Complex processing and cost-intensive raw materials make them unattractive for series parts, especially for industrial sectors with severe cost pressures, like automotive industry. Actually, there is a lack of lightweight materials for applications in an intermediate temperature range between $300^{\circ} \mathrm{C}$ and $1000{ }^{\circ} \mathrm{C}$, where PMC and light metals are not applicable anymore. CMC, however, are too expensive.

Hybrid-CMC combining a high thermal stability and good tribological behavior in the range of ceramic composites and cost-efficient elaborated full-scale series production in PMC technology are the most suitable solution to bridge this gap. Fiber reinforced polymer derived ceramics (PDC) are a promising composite material for these requirements. Polymer derived ceramics are manufactured from silicon containing precursors, which are converted into ceramics by a controlled chemical crosslinking and pyrolysis process [7]. This thermochemical transformation from polymer to ceramic is associated with a distinct mass loss and a certain shrinkage, which involve residual stresses and porosity. Due to the high loss in volume, manufacturing of PDC bulk ceramics is difficult. Fiber reinforcement and ceramic filler powders are used to reduce this shrinkage. Due to the availability on the market, the inexpensive price and the easy processability, polysiloxanes are the most promising matrix raw material for an intermediate temperature composite [8,9]. After polymerization of the siloxane, the green body is pyrolyzed to an amorphous or glassy SiOC ceramic.

The goals of the present article are as follows:

- Reviewing the most prominent fields of application and engineering solutions developed at the Institute for Manufacturing Technologies of Ceramic Components and Composites for Hybrid-CMC in Section 2.

- Presenting the results of the thermal resistivity analysis effectuated on basalt fiber reinforced SiOC samples manufactured by Resin Transfer Molding (RTM) in Section 3, Section 4, Section 5, and Section 6.

\section{Applications of Hybrid-CMC (Ceramic Matrix Composite)}

This processing route allows the adaptation of matured production technologies of PMC for the manufacturing of Hybrid-CMC components. In order to qualify the material for series applications, 
manufacturing technologies like Resin Transfer Moulding (RTM), filament winding, Pultrusion, or axial warm pressing techniques have been employed.

Basalt fiber reinforced SiOC composites feature significantly increased tribological properties in comparison to pure polymeric composite materials. The elevated hardness of the basalt fibers and the adjustable hardness of the matrix, which depends on the ceramization grade, enable a wide range of applications with tribological load. $\mathrm{B}_{\mathrm{f}} / \mathrm{SiOC}$ brake pads were evaluated exhibiting a high and constant coefficient of friction over a broad band of speed (see Figure $2 b, c)$. In comparison with grey cast iron brake rotors, reduced density and no flying sparks are the most important benefits. This last requirement is essential for elevator systems in skyscrapers in order to eliminate the risk of fire (see Figure 3). $\mathrm{B}_{\mathrm{f}} / \mathrm{SiOC}$ brake rotors have also been manufactured and tested (see Figure 2a). This material selection could be a competitive alternative to $\mathrm{C} / \mathrm{SiC}$ or $\mathrm{C} / \mathrm{C}$ materials for friction applications in e-mobility vehicles and (motor-)cycles [8].
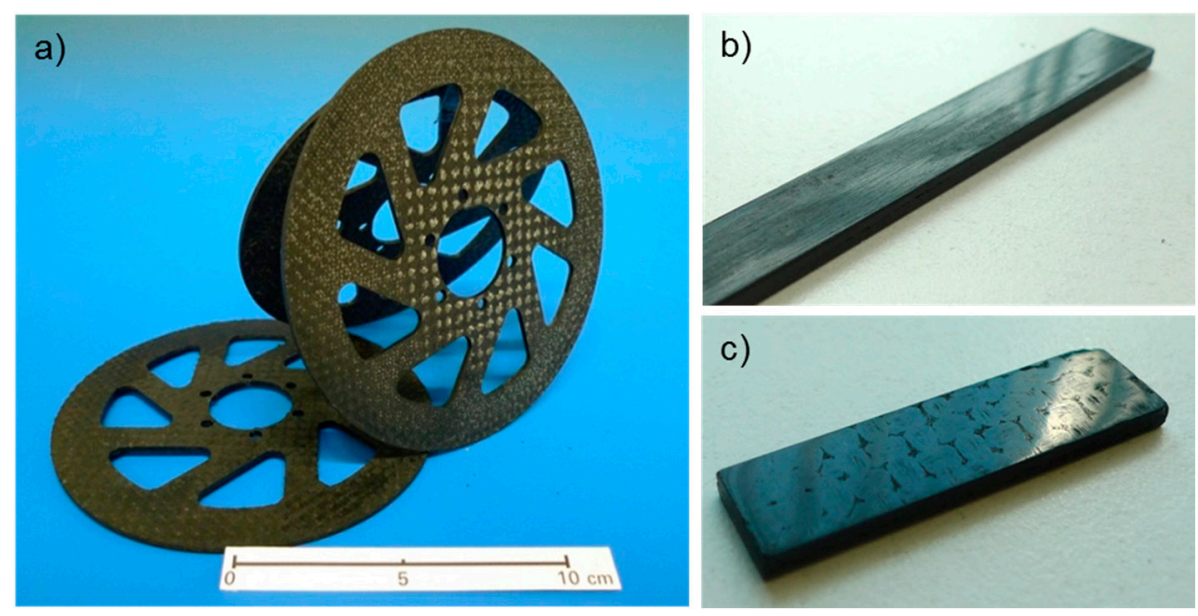

Figure 2. Tribology applications of Hybrid-CMC (Ceramic Matrix Composites): (a) bike brake discs; (b) Unidirectional reinforced composite friction pad; (c) 2D reinforced composite friction pad.
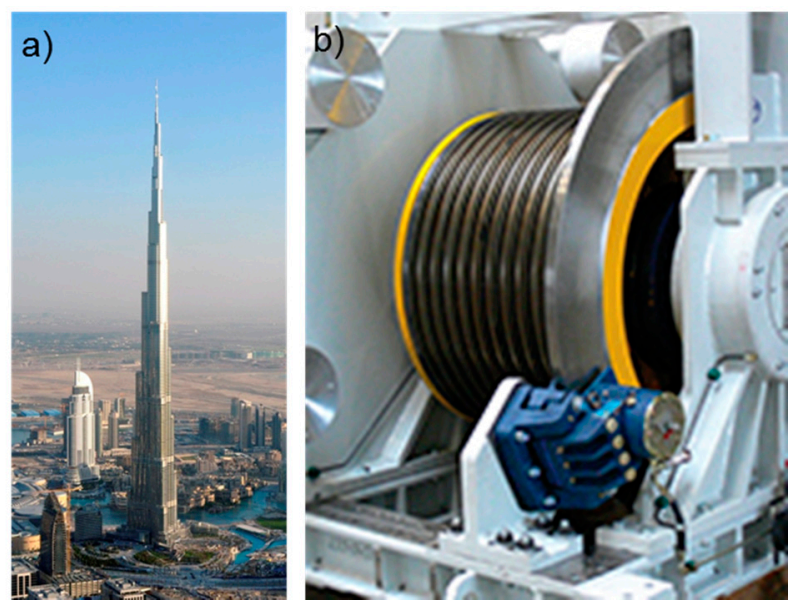

Figure 3. Tribology applications of Hybrid-CMC (Ceramic Matrix Composite): (a) Burj Khalifa building [10]; (b) Elevator disc brakes for use in skyscrapers [11].

The suitability of $\mathrm{B}_{\mathrm{f}} / \mathrm{SiOC}$ in fire protection has been also evaluated [12]. The most prominent conclusions are that the semi-ceramic composite is absolutely non-inflammable and without gaseous by-products or smoke. Low thermal conductivity of the fibers and porosity of the matrix have a positive effect on the low thermal conductivity of the whole component. Even under extreme temperatures of more than $900^{\circ} \mathrm{C}$, the material shows a significant residual strength. A notable application of $\mathrm{B}_{\mathrm{f}} / \mathrm{SiOC}$ was the exhaust duct of the Porsche 919 LMP1 racing car at the $24 \mathrm{~h}$ Le Mans race (see Figure $4 \mathrm{~b}$ ). This 
component was manufactured via RTM and tested in prototype over a full $24 \mathrm{~h}$ racing distance. The component withstood the harsh conditions regarding thermal stability and mechanical impact.
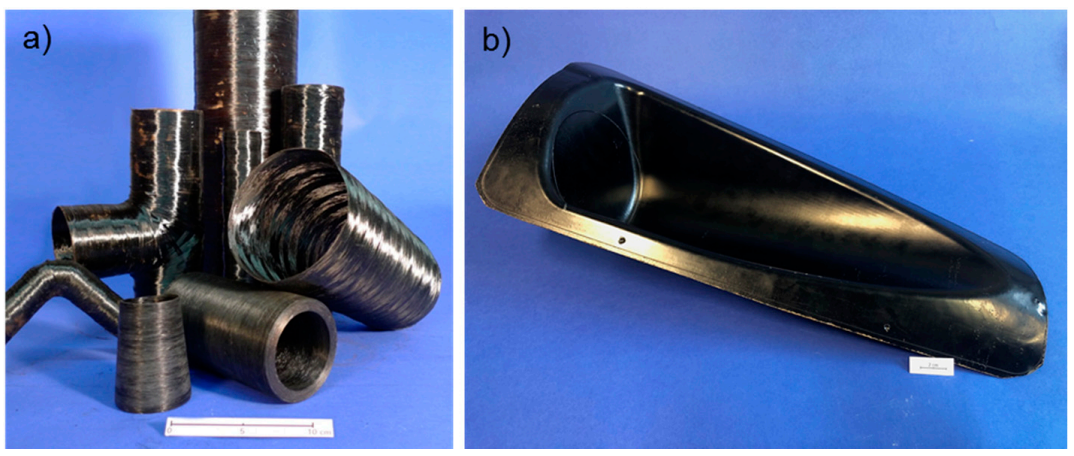

Figure 4. Thermal resistivity applications of Hybrid-CMC (Ceramic Matrix Composite): (a) Exhaust tubes with different geometries and wall thickness; (b) Exhaust duct of Porsche LMP1 racing car.

\section{Experimental}

Plain weave basalt fiber fabrics with an areal weight of $800 \mathrm{~g} / \mathrm{cm}^{2}$ and rovings manufactured by Kamenny Vek (Dubna, Russia) were used in this study. In order to compare the thermal and oxidation resistance of $\mathrm{B}_{\mathrm{f}} / \mathrm{SiOC}$ with $\mathrm{C}_{\mathrm{f}} / \mathrm{SiOC}$, plain weave carbon fiber fabrics with an areal weight of $400 \mathrm{~g} / \mathrm{cm}^{2}$ and rovings manufactured by Dowaksa (Istanbul, Turkey) were employed as reference reinforcement. A commercially available methylphenylvinylhydrogen polysiloxane, Silres ${ }^{\circledR}$ H62C produced by Wacker Chemie AG (Burghausen, Germany), was used as resin for the infiltration process. The shrinkage of the matrix was not modified by the use of active or passive fillers.

Square plates with $200 \mathrm{~mm}$ side length and $3 \mathrm{~mm}$ thickness with carbon and basalt fabric reinforcement were manufactured via Resin Transfer Molding. The RTM equipment from Composite Integration Ltd. (Saltash, UK) was modified at IFKB to meet the processing requirements of polysiloxanes [13]. Additionally, the mold design was optimized in terms of infiltration and curing behavior of polysiloxane in cooperation with WingsAndMore GmbH \& Co. KG (Ebersbach, Germany). In order to optimize the viscosity of the resin, the aluminum RTM mold was preheated to a temperature of $80^{\circ} \mathrm{C}$. After injection of the precursor (polysiloxane) into the dry fiber preforms, the resin was cured in the closed mold at a temperature of $180^{\circ} \mathrm{C}$. In order to complete the crosslinking process of the polysiloxane, the shaped plate (green body) was extracted from the mold and cured at $250{ }^{\circ} \mathrm{C}$ for $2 \mathrm{~h}$ in a drying oven. In this stage (green body), the material is a fiber reinforced PMC with a polysiloxane matrix. No pyrolysis or re-infiltration processing were performed to the samples. The polymer-ceramic transformation was effectuated during the next step (thermal exposure).

Produced basalt fiber reinforced plates were cut in 60 samples of dimensions $150 \mathrm{~mm} \times 20 \mathrm{~mm}$ for the thermal exposure tests. One sample of the same dimensions was cut from the carbon fiber reinforced plate.

In order to compare the thermal resistivity and oxidation resistance of carbon and basalt fiber reinforced $\mathrm{SiOC}, \mathrm{B}_{\mathrm{f}} / \mathrm{SiOC}$ samples were exposed to temperatures between 650 and $1250{ }^{\circ} \mathrm{C}$ in $150^{\circ} \mathrm{C}$-steps in air atmosphere. Exposure times of 1, 2, 6, 24, and 50 h were effected. Three $\mathrm{B}_{\mathrm{f}} / \mathrm{SiOC}$ samples were tested under each exposure condition. In order to perform the mentioned comparison, one sample of $\mathrm{C}_{\mathrm{f}} / \mathrm{SiOC}$ was exposed during $24 \mathrm{~h}$ to $500{ }^{\circ} \mathrm{C}$ in air using the same oven. The reason for aging just one carbon fiber reinforced sample was to try to avoid a massive air contamination at the laboratory with low-diameter oxidized carbon filaments, which can lead to pulmonary diseases.

Samples were mechanically characterized after exposures by Impulse Excitation Technique (RFDA Basic, IMCE, Genk, Belgium) and by Interlaminar Shear Strength (ILSS) tests. This last one consisted of a three-point bending test with short support span (5 times the thickness of the plates) performed with a Z100 universal testing machine manufactured by Zwick Roell (Ulm, Germany) according to the standard DIN 658-5 [14]. This option is the preferred one for the characterization of the Interlaminar 
Shear Strength (ILSS) of fabric reinforced composites. Three samples were characterized for every different thermal treatment.

Samples were also automatically ground, lapped, and polished with $15 \mu \mathrm{m}, 6 \mu \mathrm{m}$, and $1 \mu \mathrm{m}$ diamond suspension until a mirror-like surface was obtained (Struers ApS, Ballerup, Denmark). Optical micrographs of polished samples were taken with a light optical microscope (MEF4M, Leica, Wetzlar, Germany). The porosity of the thermally treated samples was measured using a mercury porosimeter Pascal 140/440 (CEInstruments, United Kingdom). One single sample for every treatment was tested.

\section{Results}

Figure 5 shows the appearance of $\mathrm{B}_{\mathrm{f}} / \mathrm{SiOC}$ and $\mathrm{C}_{\mathrm{f}} / \mathrm{SiOC}$ samples after thermal treatments. It should be underlined that after a $24 \mathrm{~h}$ exposure to $1200{ }^{\circ} \mathrm{C}$ in air, the basalt fiber phase of the $\mathrm{B}_{\mathrm{f}} / \mathrm{SiOC}$ samples seemed to be solidified after a melting process (see Figure $5 \mathrm{c}$ ). This observation means that the melting or softening point of the employed fiber charge is not higher than $1250^{\circ} \mathrm{C}$. Therefore, no further exposure at $1250^{\circ} \mathrm{C}$ were performed.

$\mathrm{B}_{\mathrm{f}} / \mathrm{SiOC}$ samples after every thermal exposure, even at the most demanding conditions $\left(1100{ }^{\circ} \mathrm{C}\right.$ for $50 \mathrm{~h}$ ), showed a certain thermal stability. In contrast to basalt fiber reinforced samples, the carbon fiber reinforced one was reduced to ashes after a $50 \mathrm{~h}$ exposure at $500{ }^{\circ} \mathrm{C}$ in air. It was not possible for the operator to remove the sample from the oven for further characterization. After taking the image of Figure $5 d$, a part of the obtained particles was introduced in a plastic zip-lock bag and the rest of the carbon fiber reinforced sample was removed from the oven with a vacuum cleaner. Therefore, no results about mechanical properties of $\mathrm{C}_{\mathrm{f}} / \mathrm{SiOC}$ can be found in this manuscript.
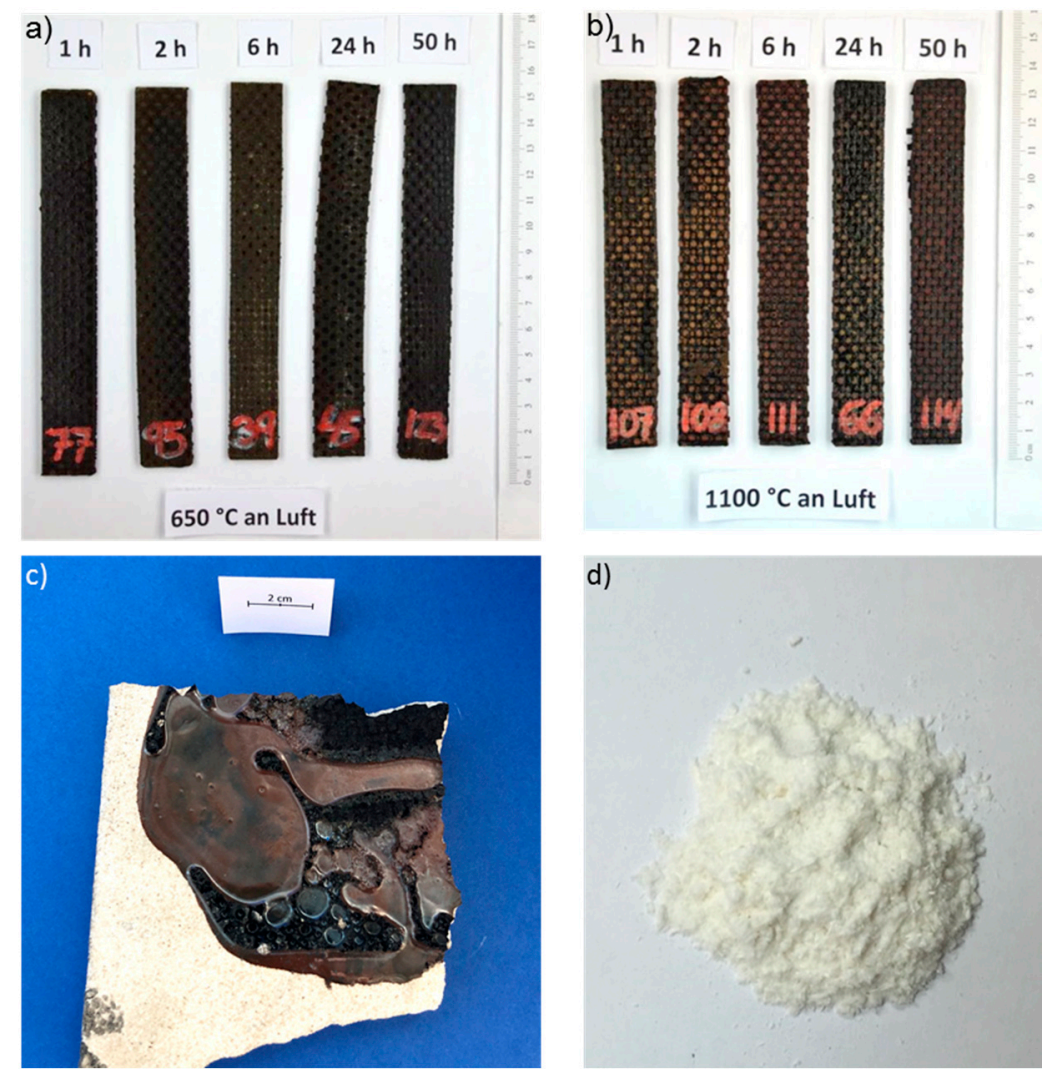

Figure 5. Effect of thermal exposure in air on Hybrid-CMC (Ceramic Matrix Composites) samples: (a) $\mathrm{B}_{\mathrm{f}} / \mathrm{SiOC}$ after exposures of $1 \mathrm{~h}, 2 \mathrm{~h}, 6 \mathrm{~h}, 24 \mathrm{~h}$ and $50 \mathrm{~h}$ in air at $650{ }^{\circ} \mathrm{C},(\mathbf{b}) \mathrm{B}_{\mathrm{f}} / \mathrm{SiOC}$ after exposures of $1 \mathrm{~h}, 2 \mathrm{~h}, 6 \mathrm{~h}, 24 \mathrm{~h}$ and $50 \mathrm{~h}$ in air at $1100{ }^{\circ} \mathrm{C} ;(\mathbf{c}) \mathrm{B}_{\mathrm{f}} / \mathrm{SiOC}$ after exposure $24 \mathrm{~h}$ in air at $1250{ }^{\circ} \mathrm{C} ;(\mathrm{d}) \mathrm{C}_{\mathrm{f}} / \mathrm{SiOC}$ after exposure of $24 \mathrm{~h}$ in air at $500{ }^{\circ} \mathrm{C}$. 
The morphology of the composite material was analyzed by means of optical microscopy. For samples treated with temperatures above $800{ }^{\circ} \mathrm{C}$, crystallization effects at the filament surfaces were detected (see Figure 6). This crystallization effect of the fiber was not observed for samples exposed to $650{ }^{\circ} \mathrm{C}$ (see Figure 6 left). This phenomenon was already mentioned in a previous publication for samples pyrolyzed at $750{ }^{\circ} \mathrm{C}$ and $850{ }^{\circ} \mathrm{C}$ under $\mathrm{N}_{2}$ atmosphere [13]. For a treatment at $1000{ }^{\circ} \mathrm{C}$, these crystals seem to emerge to the outer surface of the filaments (see Figure 6 right). This behavior was again already mentioned in the same previous publication [13].
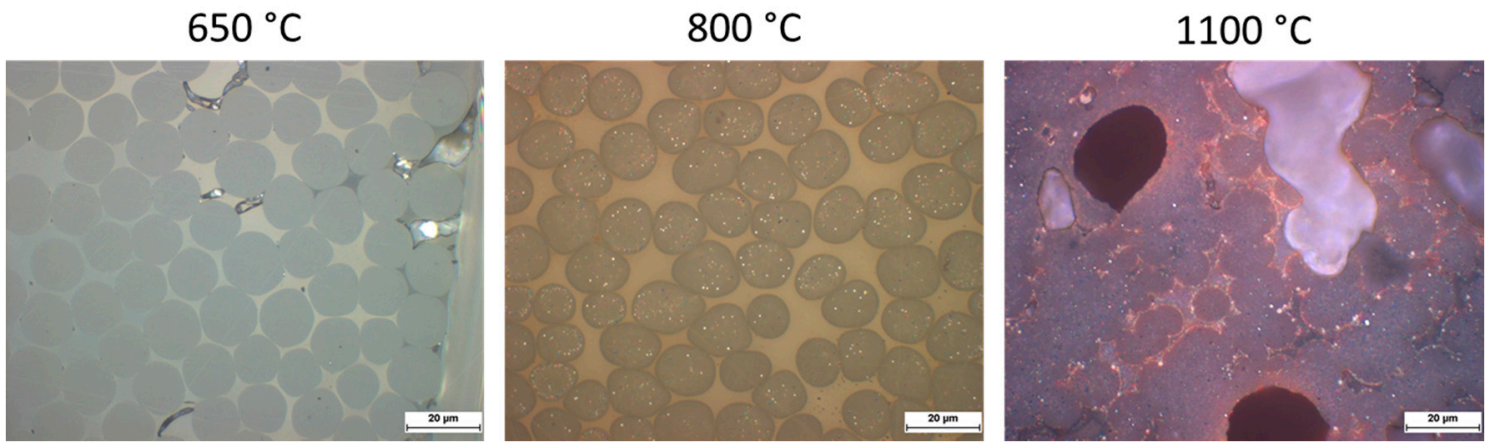

Figure 6. Cross section optical micrographs of $\mathrm{B}_{\mathrm{f}} / \mathrm{SiOC}$ after exposures of $6 \mathrm{~h}$ in air at $650{ }^{\circ} \mathrm{C}, 800{ }^{\circ} \mathrm{C}$ and $1100{ }^{\circ} \mathrm{C}$.

Another observed tendency is the variation and irregularity of the fiber geometry by increase of treating temperature. In contrast to the perfectly circular shapes of basalt fibers before thermal treatments, the filaments of samples exposed to temperatures of at least $650{ }^{\circ} \mathrm{C}$ show a reduced or deformed circular shape. This behavior becomes even more significant for composites treated at $800{ }^{\circ} \mathrm{C}$ and above. As observed in Figure 7, fibers present completely inhomogeneous, slightly elliptical shapes. Moreover, a kind of coalescence effect seems to take place by increase of treating time, tending to make the filaments fuse with each other to create larger phases. The compressive stresses induced by the sintering plates in the oven may further contribute to this consolidation effect.
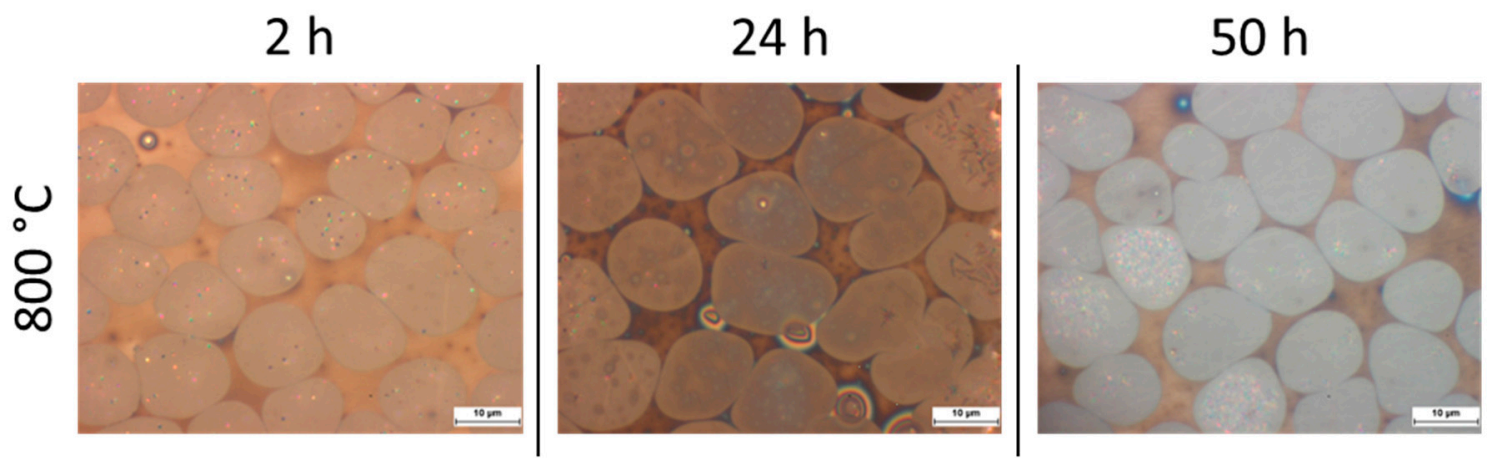

Figure 7. Cross section optical micrographs of $\mathrm{B}_{\mathrm{f}} / \mathrm{SiOC}$ after exposures of $2 \mathrm{~h}, 24 \mathrm{~h}$, and $50 \mathrm{~h}$ at $800{ }^{\circ} \mathrm{C}$ in air.

Regarding the samples treated at $1100{ }^{\circ} \mathrm{C}$, fiber shapes are only visible on the micrograph of the $1 \mathrm{~h}$ exposure sample $\mathrm{h}$ (see Figure 8 left). After longer treatments, fibers and matrix become one single phase and no fiber/matrix interface is visible anymore (see Figure 8 middle and right). Some of the former fibers are perceptible regarding ready-grown crystals on the surface. The total porosity after treatments at $1100{ }^{\circ} \mathrm{C}$ achieves rapidly values of $23 \%$ after the first hour and reaches a stationary value between $33 \%$ and $35 \%$ for $6 \mathrm{~h}, 24 \mathrm{~h}$, and $50 \mathrm{~h}$ exposures (see Table 1). Regarding the relative pore volume distribution, the most frequent pore size for these samples is about $10 \mu \mathrm{m}$ (see Figure 9). 
$1100{ }^{\circ} \mathrm{C}$ treated samples present not only the highest total porosity, but also the major concentration of big pores, especially in the range of 3-40 $\mu \mathrm{m}$.
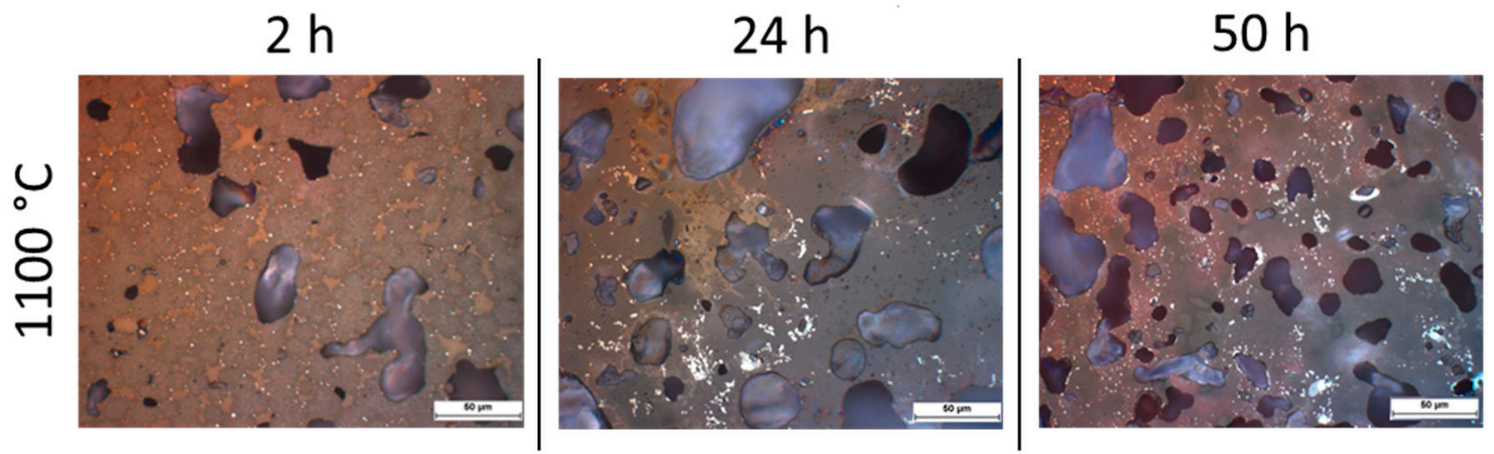

Figure 8. Cross section optical micrographs of $\mathrm{B}_{\mathrm{f}} / \mathrm{SiOC}$ samples after exposures of $2 \mathrm{~h}, 24 \mathrm{~h}$, and $50 \mathrm{~h}$ in air at $1100{ }^{\circ} \mathrm{C}$.

Table 1. Total porosity of $\mathrm{B}_{\mathrm{f}} / \mathrm{SiOC}$ samples after the thermal exposures [\%].

\begin{tabular}{cccccc}
\hline & $\mathbf{1 ~ h}$ & $\mathbf{2 ~ h}$ & $\mathbf{6 ~ h}$ & $\mathbf{2 4} \mathbf{h}$ & $\mathbf{5 0 ~ h}$ \\
\hline $\mathbf{6 5 0}{ }^{\circ} \mathbf{C}$ & 14.1 & 15.6 & 17.1 & 16.8 & 16.2 \\
\hline $\mathbf{8 0 0}{ }^{\circ} \mathbf{C}$ & 13.0 & 16.1 & 16.9 & 13.9 & 19.6 \\
\hline $\mathbf{9 5 0}{ }^{\circ} \mathbf{C}$ & 18.7 & 25.3 & 25.5 & 23.5 & 29.7 \\
\hline $\mathbf{1 1 0 0}{ }^{\circ} \mathbf{C}$ & 23.1 & 24.7 & 33.4 & 35.1 & 32.1 \\
\hline
\end{tabular}

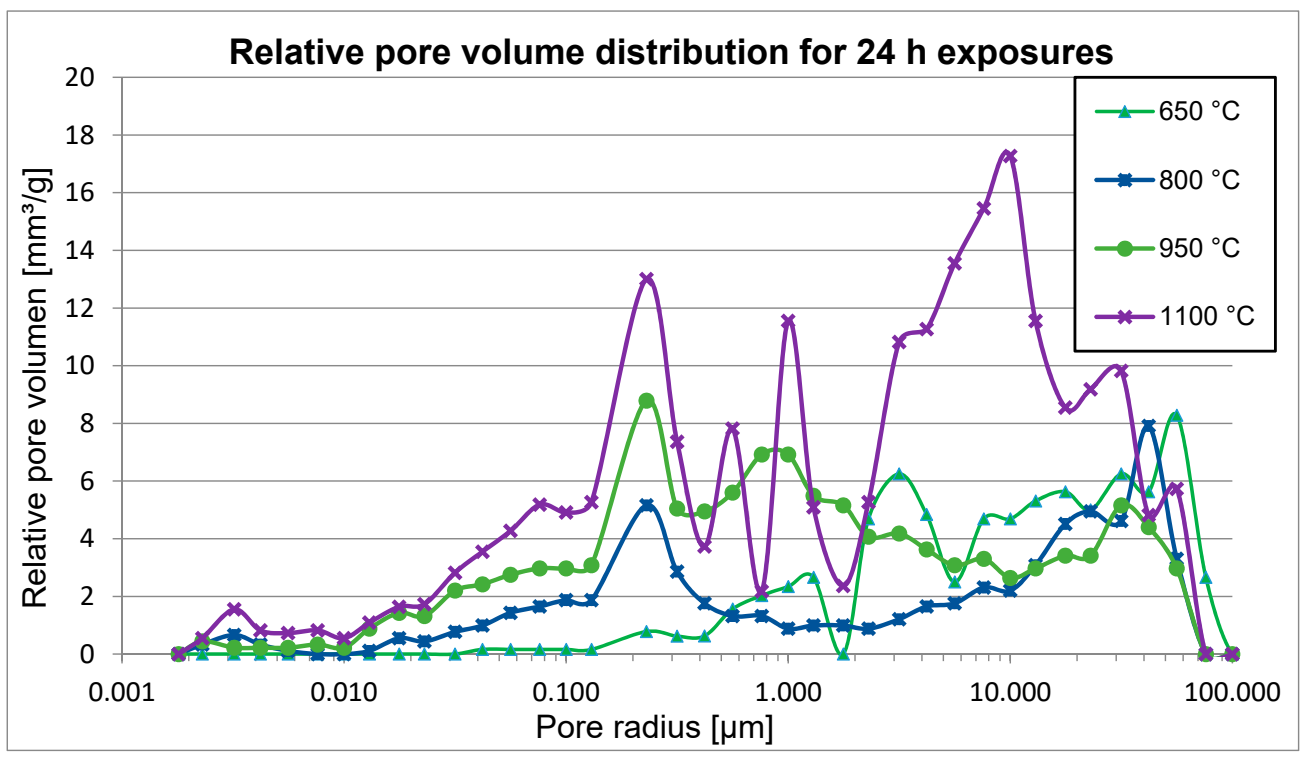

Figure 9. Relative pore volume distribution for $\mathrm{B}_{\mathrm{f}} / \mathrm{SiOC}$ after exposures of $24 \mathrm{~h}$ in air at $650{ }^{\circ} \mathrm{C}, 800{ }^{\circ} \mathrm{C}$, $950{ }^{\circ} \mathrm{C}$, and $1100{ }^{\circ} \mathrm{C}$.

Figure 10 shows the results of interlaminar shear strength measurements for all the samples. Highest ILSS values were observed for samples exposed to $800^{\circ} \mathrm{C}$. There is even an apparently positive time decency for this temperature range. However, this effect is undermined by the high standard deviation of samples after $50 \mathrm{~h}$ exposures. The same increase of ILSS with time is observed for $650{ }^{\circ} \mathrm{C}$. $950^{\circ} \mathrm{C}$ and $1100{ }^{\circ} \mathrm{C}$ samples exhibit nearly constant ILSS values for time increments. It should be also concluded that measurements of $1100{ }^{\circ} \mathrm{C}$ samples do not represent ILSS values anymore. As observed in the optical micrographs, no layered structure is present in these samples after the exposure. 


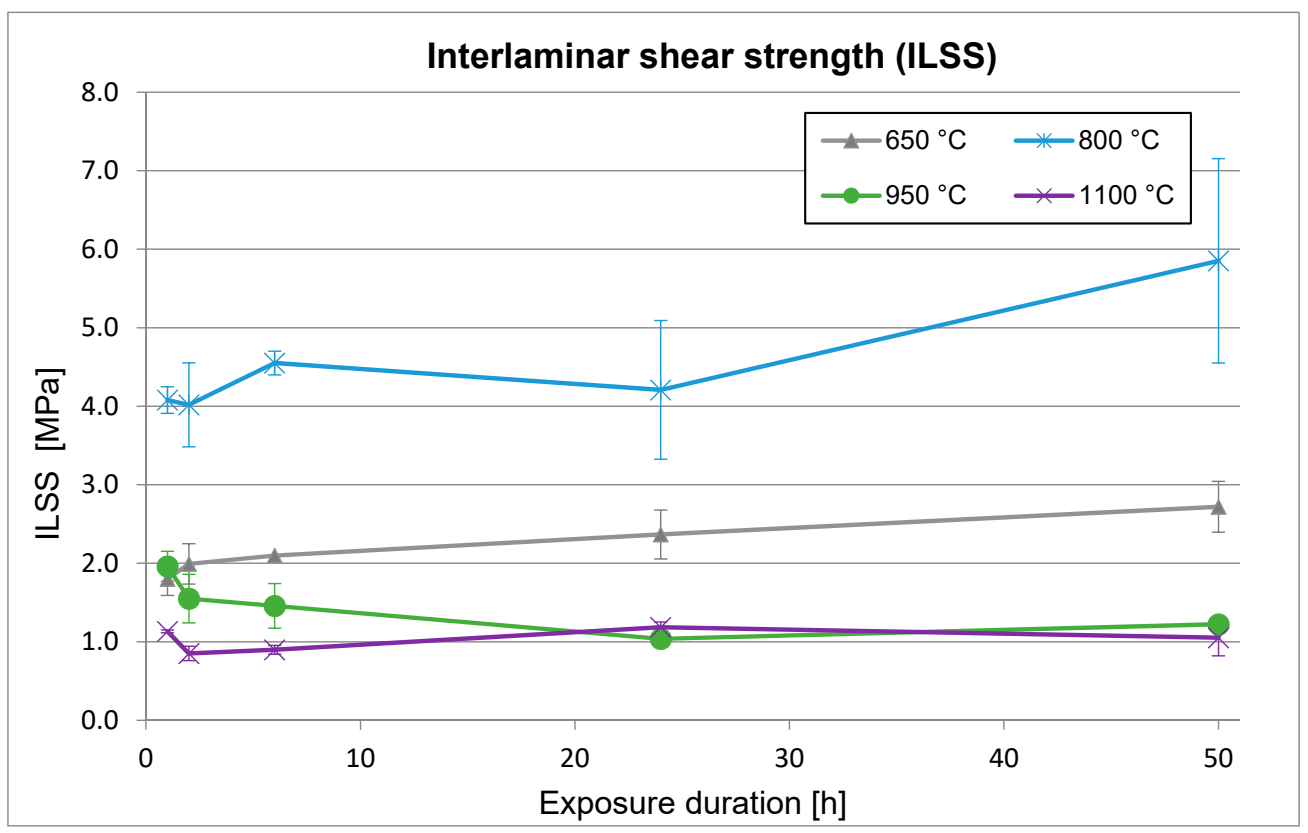

Figure 10. ILSS values of $\mathrm{B}_{\mathrm{f}} / \mathrm{SiOC}$ samples after exposures of $1 \mathrm{~h}, 2 \mathrm{~h}, 6 \mathrm{~h}, 24 \mathrm{~h}$, and $50 \mathrm{~h}$ in air at $650{ }^{\circ} \mathrm{C}$, $800{ }^{\circ} \mathrm{C}, 950^{\circ} \mathrm{C}$, and $1100{ }^{\circ} \mathrm{C}$.

Results of Young's Modulus measurements effectuated via Impulse Excitation Technique (RFDA) are shown in Figure 11. Here again, samples exposed to $800^{\circ} \mathrm{C}$ present the best values of mechanical performance. The Young's Modulus of these samples keeps between 28 and $36 \mathrm{GPa}$ for the whole curve. The positive influence of time on ILSS for $800{ }^{\circ} \mathrm{C}$ samples was not detected for stiffness. However, the values of Young's Modulus tend to recover after the $24 \mathrm{~h}$ fall. The influence of exposure time for $650{ }^{\circ} \mathrm{C}, 950^{\circ} \mathrm{C}$, and $1100{ }^{\circ} \mathrm{C}$ samples is quite moderate. Most samples achieve a stationary state after $6 \mathrm{~h}$ exposure and Young's Modulus remains constant.

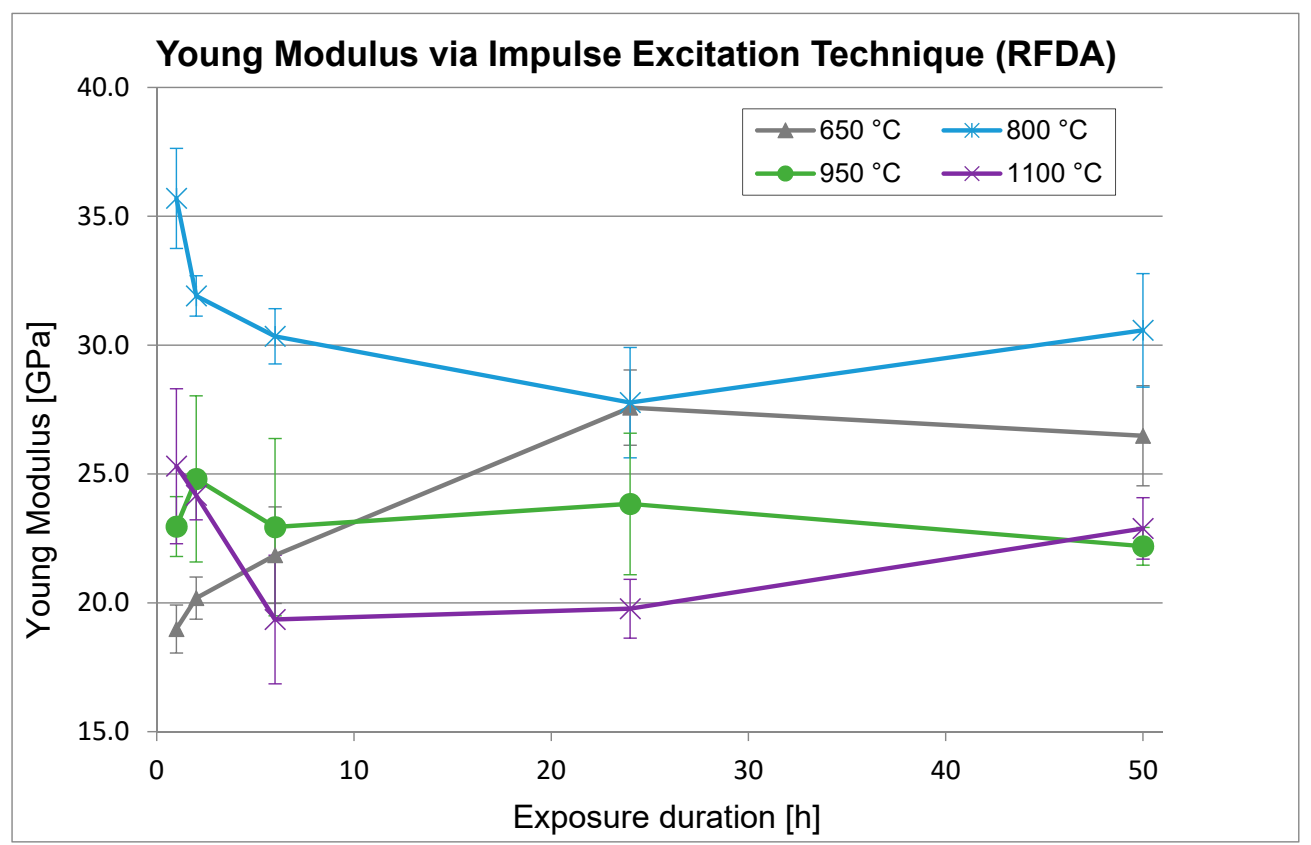

Figure 11. Young's Modulus values of $\mathrm{B}_{\mathrm{f}} / \mathrm{SiOC}$ samples after exposures of $1 \mathrm{~h}, 2 \mathrm{~h}, 6 \mathrm{~h}, 24 \mathrm{~h}$, and $50 \mathrm{~h}$ in air at $650{ }^{\circ} \mathrm{C}, 800^{\circ} \mathrm{C}, 950{ }^{\circ} \mathrm{C}$, and $1100^{\circ} \mathrm{C}$. 


\section{Discussion}

Basalt fiber reinforced polysiloxane samples show a very stable behavior after thermal exposures under the crystallization temperature of basalt fiber, which was found to be close to $850{ }^{\circ} \mathrm{C}$ in a previous study via differential thermal analysis with coupled thermogravimetry DTA/TG [13]. $\mathrm{B}_{\mathrm{f}} / \mathrm{SiOC}$ samples treated at $650{ }^{\circ} \mathrm{C}$ and $800{ }^{\circ} \mathrm{C}$ reach a steady state after 6 hours of exposure, which is maintained even after $50 \mathrm{~h}$ of treatment. The crystallization process of the fibers, confirmed by cross section optical micrographs shown in Figure 6, impairs their mechanical properties (especially their toughness). This phenomenon decreases the mechanical performance of the composite, as observed for samples exposed to $950{ }^{\circ} \mathrm{C}$ and $1100{ }^{\circ} \mathrm{C}$.

The second effect that explains the degradation of the composite below temperatures of $800{ }^{\circ} \mathrm{C}$ is the increasing porosity of the SiOC matrix. $\mathrm{B}_{\mathrm{f}} / \mathrm{SiOC}$ samples after a $50 \mathrm{~h}$ exposure to $950{ }^{\circ} \mathrm{C}$ present a porosity increase of $50 \%$ in comparison with samples treated at $800{ }^{\circ} \mathrm{C}$. This handicap of polymer derived ceramics is widely published and explained in the literature [7]. The addition of inert or active filler materials to the matrix and the substitution of this resin by another one with higher ceramic yield can lead to a reduction of porosity and shrinkage during pyrolysis and therefore to an increase of the mechanical properties.

\section{Conclusions}

SiOC derived hybrid ceramic composites with basalt fiber reinforcement were manufactured by Resin Transfer Molding technique. The materials were characterized with a special focus on their thermochemical stability and thermal resistivity. The first important conclusion is the significant difference in thermal resistivity for samples reinforced with carbon and alternatively with basalt fibers. Carbon fiber reinforced polysiloxane samples were completely degraded after a $24 \mathrm{~h}$ exposure to $500^{\circ} \mathrm{C}$ by oxidation. In contrast, basalt fiber reinforced samples exhibit a decent mechanical performance even after a 50h exposure to $1100{ }^{\circ} \mathrm{C}$ with over $20 \mathrm{GPa}$ Young's Modulus. These moderate mechanical properties are sufficient for applications, in which the component must sustain just its structural integrity and own weight at this elevated temperature range. Novel Exhaust systems and components are a suitable example of this kind of application.

However, results obtained in this study also confirmed that $\mathrm{B}_{\mathrm{f}} / \mathrm{SiOC}$ are not suitable for long time exposures to temperatures in the range of $1250{ }^{\circ} \mathrm{C}$ and above due to the softening or melting point of the basalt fibers and the observed re-crystallization with a subsequent degradation of mechanical properties.

The best mechanical performance, regarding ILSS and stiffness, was measured for up to $800{ }^{\circ} \mathrm{C}$ exposures. Therefore, this seems to be the optimal service temperature range for this family of Hybrid-CMC materials.

Author Contributions: Conceptualization, P.W.; Data curation, M.J.; Investigation, P.W.; Methodology, P.W.; Project administration, R.G.; Supervision, R.G.; Writing—original draft, M.J.; Writing—review \& editing, R.G.

Funding: This research received no external funding.

Conflicts of Interest: The authors declare no conflict of interest. The funders had no role in the design of the study; in the collection, analyses, or interpretation of data; in the writing of the manuscript, or in the decision to publish the results.

\section{References}

1. Granta Design Limited. CES Edupack. 2013. Available online: https://grantadesign.com/industry/products/ ces-selector/ (accessed on 17 April 2019).

2. Feuerwehr Sögel. Available online: https://www.noz.de/lokales/lathen/artikel/740181/windkraftanlage-inrenkenberge-ausgebrannt\#gallery\&0\&0\&740181 (accessed on 13 March 2019).

3. Markovich, T. Gallery. Available online: https://www.complex.com/sports/2012/10/gallery-25-pictures-ofsupercars-on-fire/lamborghini-murcielago (accessed on 13 March 2019). 
4. Deutsche Presse-Agentur; Frey. Available online: https://www.merkur.de/welt/ice-brand-bei-montabaurteile-von-ice-wrack-abtransportiert-strecke-weiter-gesperrt-zr-10321277.html (accessed on 13 March 2019).

5. Stimson, I.L.; Fisher, R. Design and Engineering of Carbon Brakes. Philos. Trans. R. Soc. A: Math., Phys. Eng. Sci. 1980, 294, 583-590. [CrossRef]

6. Gadow, R.; Speicher, M. Advanced Manufacturing of Ceramic Matrix Composites for Disk Brake Rotors. In Proceeding of the SAE 2003 World Congress \& Exhibition, Warrendale, PA, USA, 3 March 2003.

7. Colombo, P.; Mera, G.; Riedel, R.; Sorarù, G.D. Polymer-Derived Ceramics: 40 Years of Research and Innovation in Advanced Ceramics. J. Am. Ceram. Soc. 2010, 73, 1805-1837. [CrossRef]

8. Gadow, R.; Weichand, P. Novel Intermediate Temperature Ceramic Composites, Materials and Processing for Siloxane Based Basalt Fiber Composites. Key Eng. Mater. 2014, 611, 382-390. [CrossRef]

9. Militký, J.; Černý, M.; Jakeš, P.; Kovačič, V.; Sucharda, Z.; Glogar, P. Composite materials with basalt fibre reinforcement and pyrolysed polysiloxane matrix. Acta Res. Rep. 2008, 17, 31-36.

10. Reuters. Available online: https://www.zdf.de/kinder/logo/tag-des-wolkenkratzers-102.html (accessed on 13 March 2019).

11. Altra Industrial Motion. Available online: http://altraheavyduty.com/lifts-escalators-ap.asp (accessed on 13 March 2019).

12. Weichand, P.; Gadow, R. Competitive fiber reinforced composite materials for increased service temperature usable in exhaust systems. In 14. Internationales Stuttgarter Symposium; Springer Vieweg: Wiesbaden, Germany, 2014; pp. 509-519.

13. Weichand, P.; Gadow, R. Basalt fibre reinforced SiOC-matrix composites: Manufacturing technologies and characterisation. J. Eur. Ceram. Soc. 2015, 35, 4025-4030. [CrossRef]

14. Deutsches Institut für Normung. Hochleistungskeramik-Mechanische Eigenschaften von keramischen Verbundwerkstoffen bei Raumtemperatur. Teil 5: Bestimmung der Scherfestigkeit im Drei-Punkt-Biegeversuch mit kurzem Auflagerabstand (DIN 658-5:2002). Available online: https: //www.din.de/de/wdc-beuth:din21:39105871 (accessed on 17 April 2019).

(C) 2019 by the authors. Licensee MDPI, Basel, Switzerland. This article is an open access article distributed under the terms and conditions of the Creative Commons Attribution (CC BY) license (http://creativecommons.org/licenses/by/4.0/). 